\title{
Force prediction for single point incremental forming deduced from experimental and FEM observations
}

\author{
R. Aerens • P. Eyckens - A. Van Bael • J. R. Duflou
}

Received: 21 January 2009 / Accepted: 4 June 2009

(C) Springer-Verlag London Limited 2009

\begin{abstract}
The aim of the study was to establish practical formulae allowing to predict the forces occurring during the single point incremental forming process. This study has been based on a large set of systematic experiments on the one hand and on results of finite elements modeling simulations on the other. This led to analytical formulae allowing to compute the three main components of the force for five selected materials in function of the working conditions (sheet thickness, wall angle, tool diameter, and step down) with a good precision. Moreover, a general model has been deduced, allowing to compute an approximate value for the force for any material, based on knowledge of the tensile strength only.
\end{abstract}

Keywords Single point incremental forming $\cdot$ Rapid prototyping $\cdot$ Sheet metal forming $\cdot$ Forces $\cdot$ Process modeling

\section{Introduction}

Single point incremental forming (SPIF) is a variant of incremental forming in which flat metal sheets are gradually formed into 3D shapes using a generic tool stylus only. This new forming method is especially suitable for small batch production and rapid prototyping of sheet metal parts [1].

Depending on the sheet material and thickness, considerable forces can occur. A good knowledge of these forming forces can contribute to the preservation of the tooling and the machinery used in the process, but is especially of fundamental importance when using a robot as forming platform. Indeed, a robot is typically not a stiff structure, and due to the forming forces, the device deflects, causing important deviations to the tool path which result in errors in the geometry of the achieved parts. An important step towards solving this problem is to include a compensation for the deflection to be expected in the tool path. This is possible on two conditions: firstly, the stiffness of the robot has to be known in all its configurations, and secondly, the process forces need to be measured or predicted with sufficient accuracy. Force prediction is the topic of this paper. Previous work in this field has been performed by different authors. Ambrogio et al. [2] studied the influences of the tool diameter, the wall angle, and the sheet thickness on the axial force on the tool for three materials (AA1050-O, AA3003-O, and DC04). This provided graphs allowing to draw qualitative conclusions. Jeswiet et al. [3] and Szekeres et al. [4] developed a 
dedicated force sensor for measuring the three components of the SPIF force with encouraging initial results. The measuring system, however, seems to need further enhancements to assure systematic output. Petek et al. [5] studied the influences of the wall angle, tool rotation, tool diameter, feed rate, step down, and lubrication on the axial force for a single material (DC05). This resulted in a series of graphs allowing to draw qualitative conclusions. Iseki [6] developed an approximate formula to compute the axial and radial forces based on a simplified membrane analysis. The author checked his formula for the case of an aluminum pyramid with satisfactory results. To apply these formulae, the width of the sheet strip which is elongated has to be evaluated. This width is typically assumed to be a fraction of the tool diameter. A more exact determination would require solving the contact problem. The formula for the axial force has been checked for truncated cones in DC01. Using a fixed ratio of the tool diameter for the sheet strip, the results are diverse: in some cases, a good correlation could be concluded, while for other cases, an error of a factor two could be noted. Pohlak et al. [7] performed a similar kind of analysis using a more refined material model: Hill's second and higher order yield criteria were used for describing the anisotropy. The authors did not provide any experimental verification results for the proposed formulae. For using the formulae, firstly, as for Iseki, the width of the elongated strip has to be estimated, and secondly, the normal anisotropy coefficient and the Hill's yield criteria exponent need to be known. Silva et al. [8] proposed a thorough membrane analysis which led to an estimation the stresses and strains in the contact zone of the tool. The results were not extended to an evaluation of the forces. Duflou et al. [9, 10] made systematic tests in order to study the influence of the wall angle, tool diameter, step down, and the sheet thickness for a single material (AA3003-O). A series of graphs allows to evaluate those influences. Duflou et al. [11] also conducted a study on the forces based on an experimental design according to the socalled face-centered central composite design for the same material. Such a design was needed because of non-linear relations. The analysis yielded regression equations for the axial force and the force in a plane perpendicular to the axis of the tool. These equations are polynomials of second degree including interaction terms. This analysis approach requires 27 tests in order to build a force model for an additional material. Duflou et al. [12] also showed that, knowing the force evolution for simple geometries, it was possible to predict the force evolution for parts the geometry of which is composed of several elementary shapes.

In this paper, a new approach for the prediction of SPIF forces is presented, based on experimental results as well as analytical relations derived from finite element analysis results.

\section{Research plan}

With the aim of establishing equations allowing to compute the forming forces for different materials, the following strategy has been applied:

1. In order to measure the forces in steady-state situations, truncated cones were formed. The first problem was to find a method to measure the three main components for this geometry.

2. To examine the basic relations between the three components and the main process parameters, i.e., the sheet thicknesses, the wall angle, the tool diameter and the depth increment. This has been performed for a single material: AA3003.

3. From this analysis, to deduce the planning of experiments with five different materials (a soft aluminum alloy: AA3003, an Al-Mg alloy: AA5754, a deep drawing steel: DC01, a stainless steel: AISI 304 and a spring steel: $65 \mathrm{Cr} 2$ ).

4. To post process the results in order to derive the analytical equations for the force components. As it will appear later in the text, the equations are partially obtained using regression techniques and partially based on the physics of the process and FEM simulations.

\section{The force measurement method}

To produce the truncated cones, metal sheets were clamped along their periphery in a dedicated rig. This rig was mounted on a three-component dynamometer, a Kistler type $9265 \mathrm{~B}$, used with a multichannel charge amplifier 5017A (Fig. 1). This stiff dynamometer, of quartz type, allows to measure the three orthogonal components of a force. Let the axial component (axis of the stylus) be Fz and the two other components Fx and Fy.

During the forming, circular tool paths are executed which yields a stable signal for $\mathrm{Fz}$ and two sinusoidal signals for Fx and Fy (Fig. 2). These are the two components of the in-plane force Fxy, which is the resultant of the tangential and the radial components Ft and Fr (see Fig. 1). In order to obtain those two components, the following procedure was used.

First, the in-plane force Fxy and the angle $\psi$ between Fx and Fy are computed using the elementary formulae:

$F x y=\sqrt{F^{2}+F y^{2}}$

and

$\psi=\arctan (\mathrm{Fy} / \mathrm{Fx})$ 


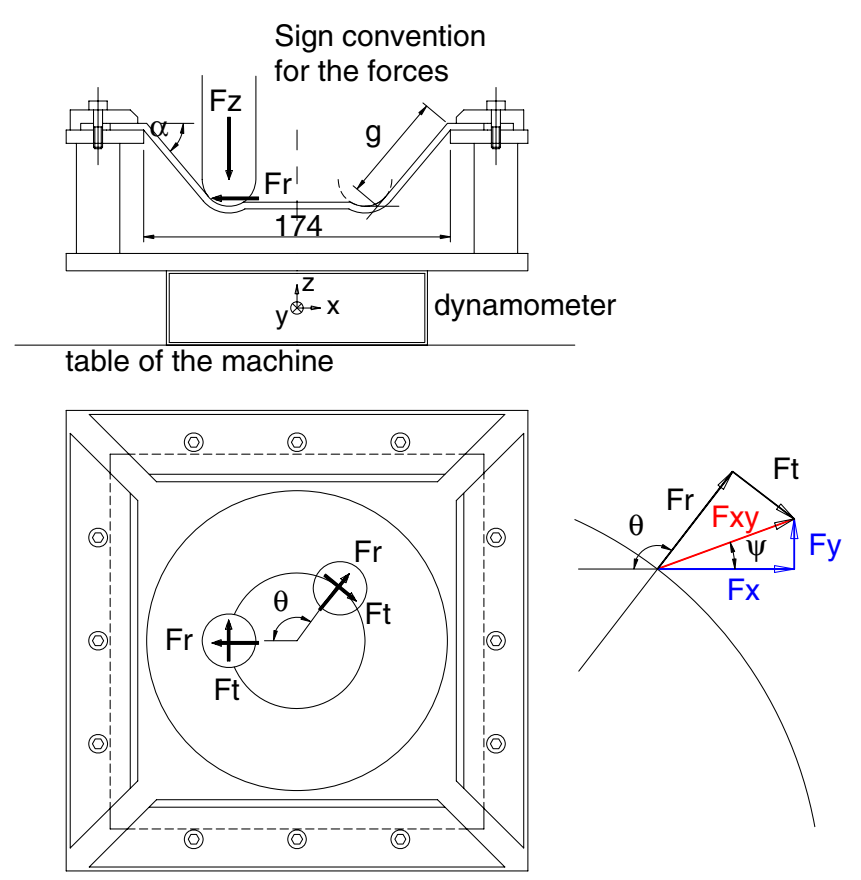

Fig. 1 Sketch of the rig mounted on the dynamometer and the relation between Fx, Fy and Ft, Fr

The cones were generated in a stepwise fashion: it means that a fixed depth increment was applied between the consecutive contours. The depth increment generates typically a pulse in the force diagram (Fig. 2), which can be used to determine the position of the tool on the circumference.

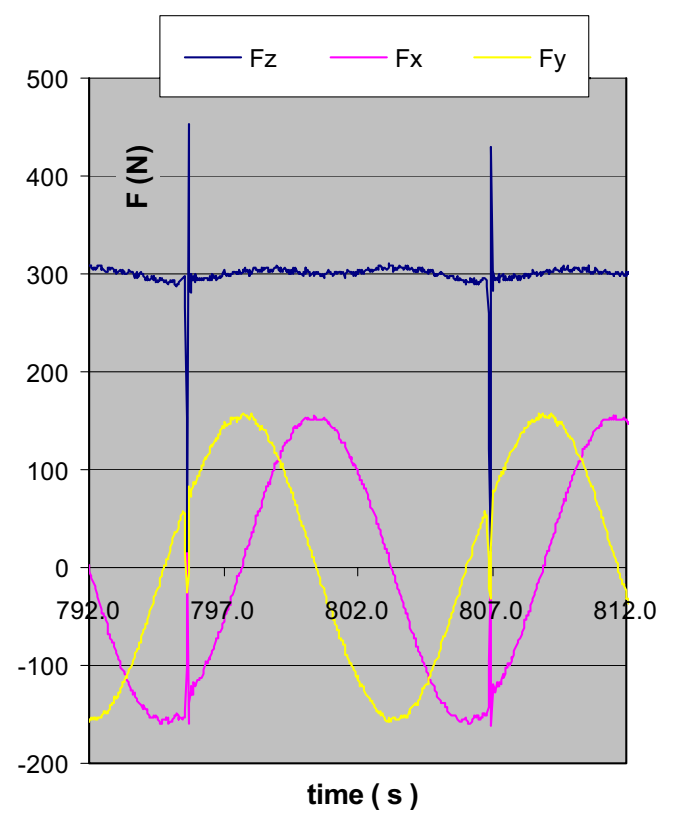

Fig. $2 \mathrm{Fx}, \mathrm{Fy}$, and $\mathrm{Fz}$ versus time

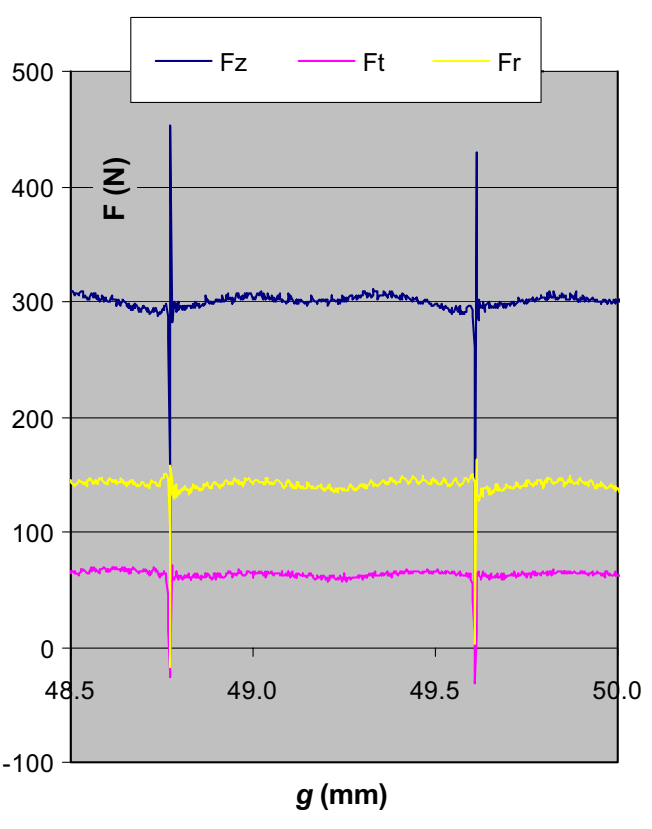

Fig. 3 Ft, Fr, and Fz versus $g$

As the tool speed is constant, the angle $\theta$ can be computed as:

$\theta=\frac{t}{T} 2 \pi$

where

$t$ time passed between the depth increment and the current position of the tool

$T$ time to perform a contour, i.e., the time between two consecutive depth increments

Depending on the position of the depth increment relative to the axes of the dynamometric table $(-x, 0$ or $0, y$ or $x, 0$ or $0,-y$ ), the tangential force component $\mathrm{Ft}$ and the radial force component $\mathrm{Fr}$ are computed with formulae like the following ones:

In the case of a depth increment in position $(-x, 0)$, as shown in Fig. 1,

$\mathrm{Ft}=\operatorname{sign}(\mathrm{Fx}) \mathrm{Fxy} \sin (\theta+\psi)$

$\mathrm{Fr}=-\operatorname{sign}(\mathrm{Fx}) \mathrm{Fxy} \cos (\theta+\psi)$

Fig. 4 Conventional and real evolution of $g$

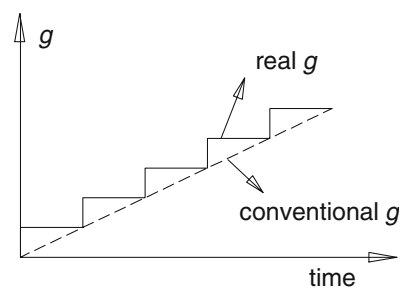


Fig. 5 Typical record of the three components of the process force versus $g$ (case of DC01, thickness $1.15 \mathrm{~mm}$, wall angle $60^{\circ}$, tool diameter $25 \mathrm{~mm}$, depth increment $1.06 \mathrm{~mm}$ )

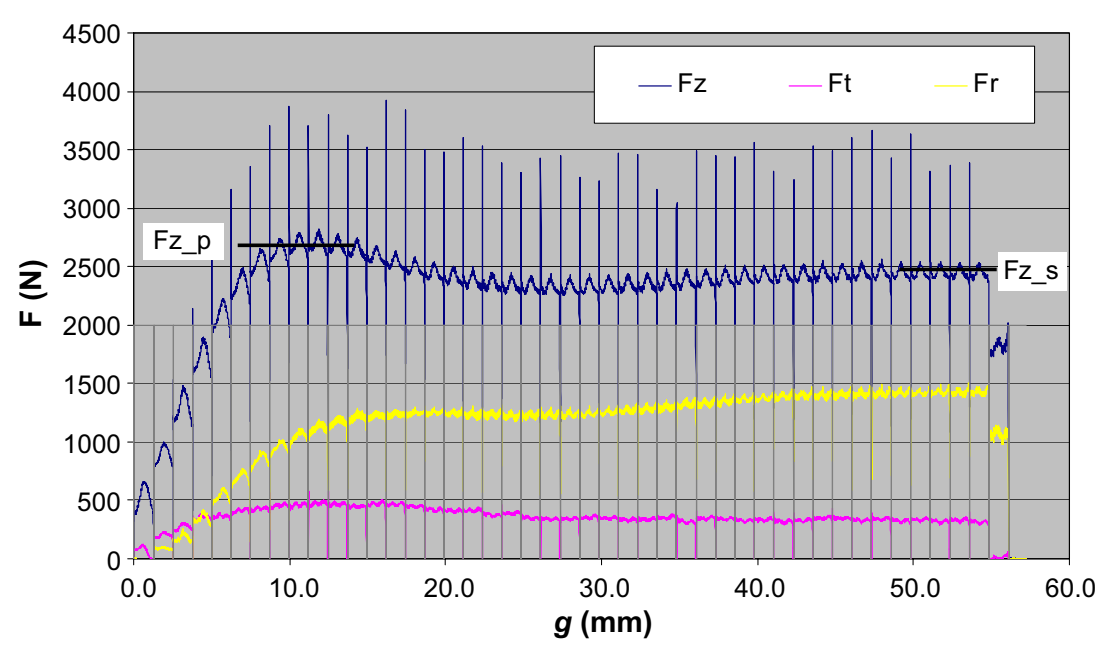

The result is shown in Fig. 3. Furthermore, in this figure, the variable "time" has been replaced by $g$ which is the length of the generating line of the cone (see Fig. 1).

For the conversion of "time" in $g$, even if in reality $g$ evolves stepwise, for the readability of the measurements, we adopted a conventional smoothed evolution of $g$ as shown in Fig. 4.

As a result of this processing, we obtain measurement results as presented in Fig. 5.

For the axial force $\mathrm{Fz}$ we retained two values: the peak value Fz_p (if present) and the steady-state value Fz_s (resp. 2,700 and 2,450 $\mathrm{N}$ in the example shown in Fig. 5). The tangential and radial forces are registered when in steady state.

\section{Preliminary study: relations between the parameters and the forces}

A preliminary study has been conducted with the aim to identify the nature of the relation that exists between each parameter and the three components of the force. Therefore, for one material (AA3003), the influence of each parameter has been observed while the other parameters were kept constant at "standard" values.

The standard values are: tool diameter $\left(d_{\mathrm{t}}\right)$ of $10 \mathrm{~mm}$, sheet thickness $(t)$ of $1.2 \mathrm{~mm}$, wall angle $(\alpha)$ of $50^{\circ}$ and depth increment $(\Delta z)$ of $0.5 \mathrm{~mm}$. The feed rate was $2,000 \mathrm{~mm} / \mathrm{min}$ and the rotational speed has been chosen so that the tool rolls on the plate at the mean radius of the contact area. Oil was used as lubricant.

\subsection{Influence of the wall angle}

The evolution of the forces in function of the wall angle $(\alpha)$, keeping the other parameters at their standard values (i.e., $d_{\mathrm{t}}=10 \mathrm{~mm}, t=1.2 \mathrm{~mm}, \Delta z=0.5 \mathrm{~mm}$ ), is shown in Fig. 6 a.
One can see that for $\mathrm{Fz} \_\mathrm{p}$ there are no measuring points for $\alpha<50^{\circ}$ reflecting the fact that no force peak was noticeable. In this case, we shall consider that steady-state values are also "peak" values. The Fz $\mathrm{p}$ is an increasing curve, while $\mathrm{Fz}_{-} \mathrm{s}$ shows a maximum value. In the same graph, the function $(\alpha \cos \alpha)$ has also been plotted with an appropriate scale factor. It is evident that $\mathrm{Fz}_{-} \mathrm{s}$ may be assumed to be proportional to $(\alpha \cos \alpha)$; physically, it means that the $\mathrm{Fz}_{-} \mathrm{s}$ is proportional to the wall angle and to the resulting wall thickness as approximated by the sine law
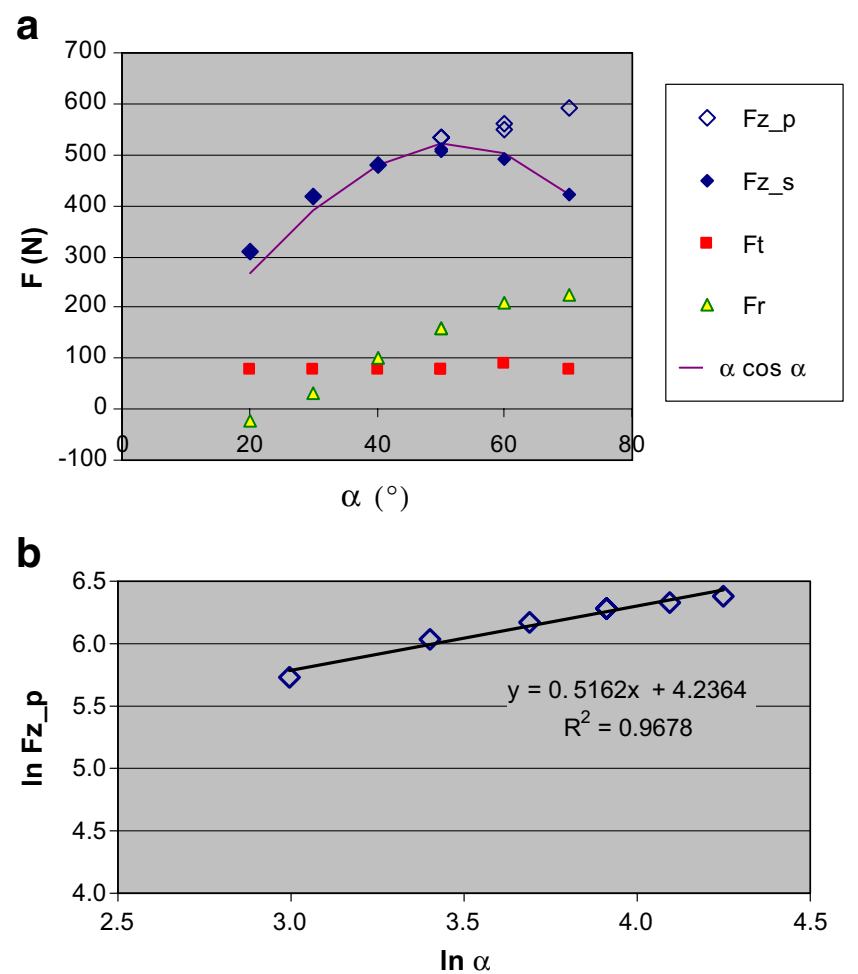

Fig. 6 Experimental forces for AA3003 in function of the wall angle (other parameters at standard settings: $d_{\mathrm{t}}=10 \mathrm{~mm}, t=1.2 \mathrm{~mm}, \Delta z=$ $0.5 \mathrm{~mm}$ ). a Linear plot; b log plot 


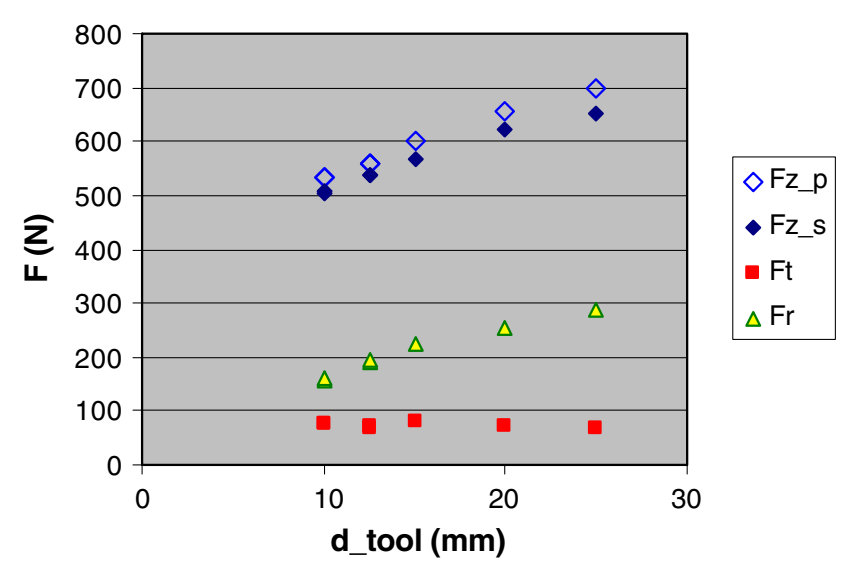

a - linear plot

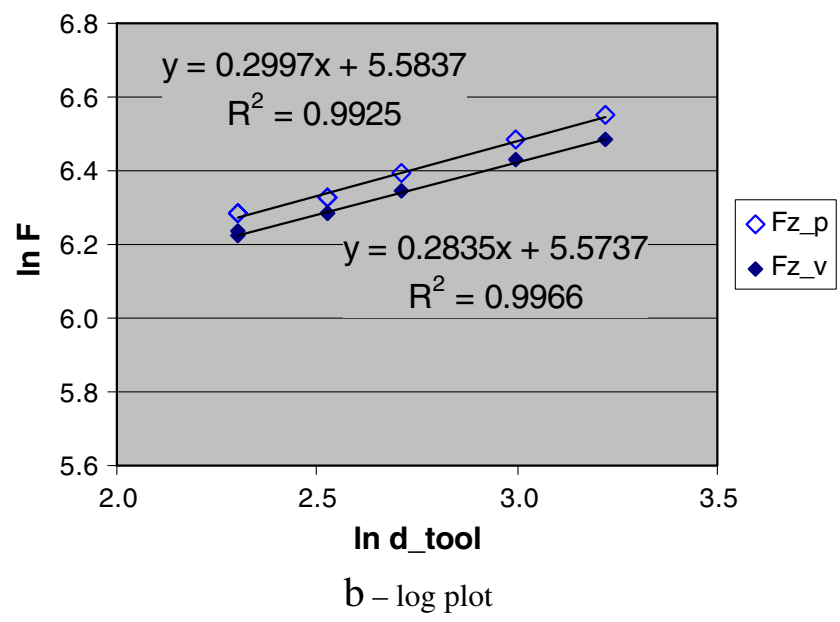

Fig. 7 Experimental forces for AA3003 in function of the tool diameter (other parameters at standard settings: $\alpha=50^{\circ}, t=1.2 \mathrm{~mm}$, $\Delta z=0.5 \mathrm{~mm}$ ). a Linear plot; b log plot

[13]. The same trend could be observed for the other materials except for the stainless steel AISI 304. For this last material, Fz_s increases till about $60^{\circ}$ and then drops abruptly.

The tangential component $\mathrm{Ft}$ is small and nearly constant.

The radial component $\mathrm{Fr}$ is negative for small wall angles and becomes positive from $23^{\circ}$ onwards. During forming, a contact groove is formed in the cone bottom (Fig. 1). For small angles, the inner part of the groove obviously exerts a higher radial reaction force in the outward direction, than the outer part of the groove in the inward direction. The phenomenon of a negative radial force component has also been observed in finite element simulations of the SPIF forming of truncated cones [14].

The curve of Fz $\_$has also been plotted in a log-log diagram (Fig. 6b). It can be observed that the relation between the logarithm of Fz_p and the logarithm of $\alpha$ can be accurately approximated as linear. In this figure, the equation of the linear regression and its coefficient of determination (squared correlation coefficient) $R^{2}$ are indicated.

\subsection{Influence of the tool diameter}

Tests have been performed with tool diameters $\left(d_{t}\right)$ of 10 , $12.7,15,20$, and $25 \mathrm{~mm}$, keeping the other parameters at their standard values (i.e., $\alpha=50^{\circ}, t=1.2 \mathrm{~mm}, \Delta z=0.5 \mathrm{~mm}$ ). Results are plotted in Fig. 7a.

It can be noticed that $\mathrm{Ft}$ is small and remains nearly constant. The curves of $\mathrm{Fz} \_\mathrm{p}$ an $\mathrm{Fz}_{-} \mathrm{s}$ have also been plotted in a log-log diagram (Fig. 7b). The high coefficients of determination indicate good linear relations between the logarithm of $\mathrm{Fz}_{-} \mathrm{p}$ and $\mathrm{Fz}_{-} \mathrm{s}$ and the logarithm of the tool diameter.

\subsection{Influence of the sheet thickness}

Tests have been performed with sheet thicknesses $(t)$ of $0.85,1.20,1.50$, and $2.00 \mathrm{~mm}$, keeping the other parameters at their standard values (i.e., $\alpha=50^{\circ}, d_{\mathrm{t}}=$ $10 \mathrm{~mm}, \Delta z=0.5 \mathrm{~mm}$ ). Results are plotted in Fig. 8a.
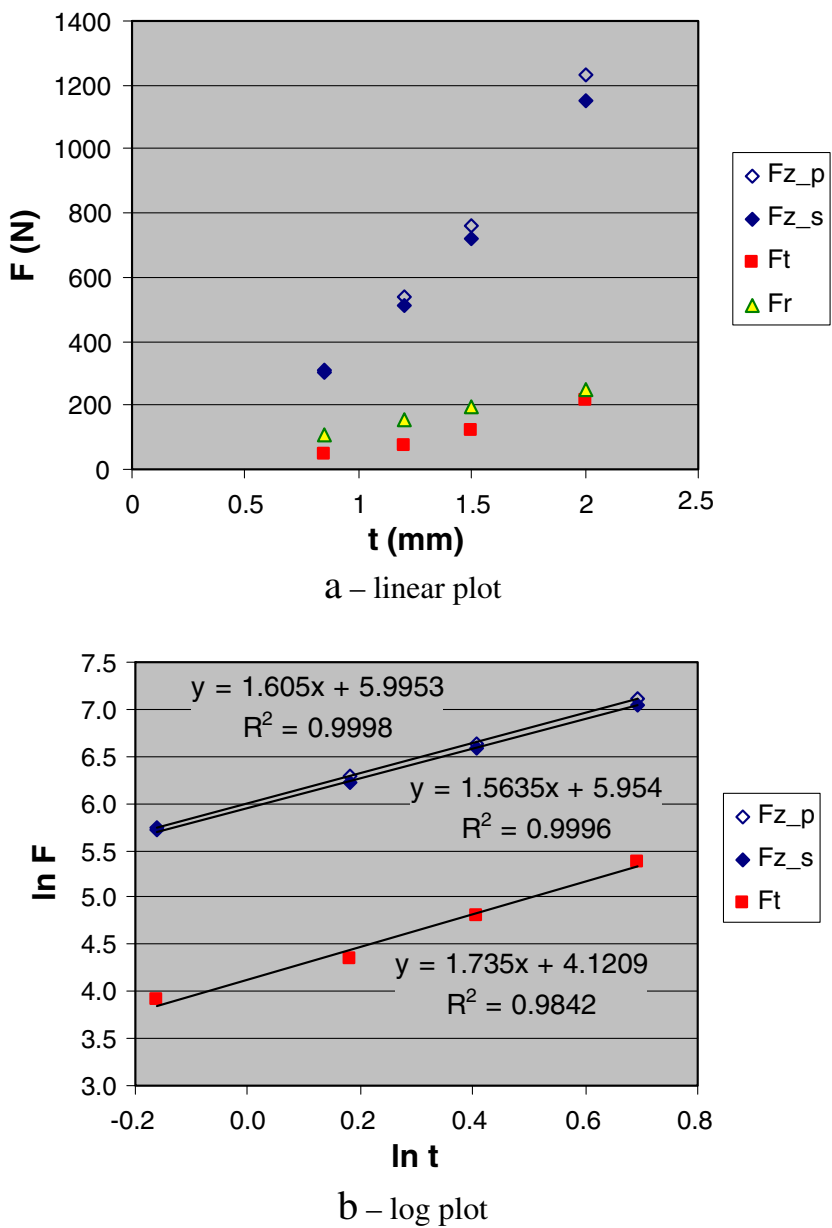

Fig. 8 Experimental forces for AA3003 in function of the sheet thickness (other parameters at standard settings: $\alpha=50^{\circ}, d_{\mathrm{t}}=10 \mathrm{~mm}$, $\Delta z=0.5 \mathrm{~mm})$. a Linear plot; $\mathbf{b} \log$ plot 


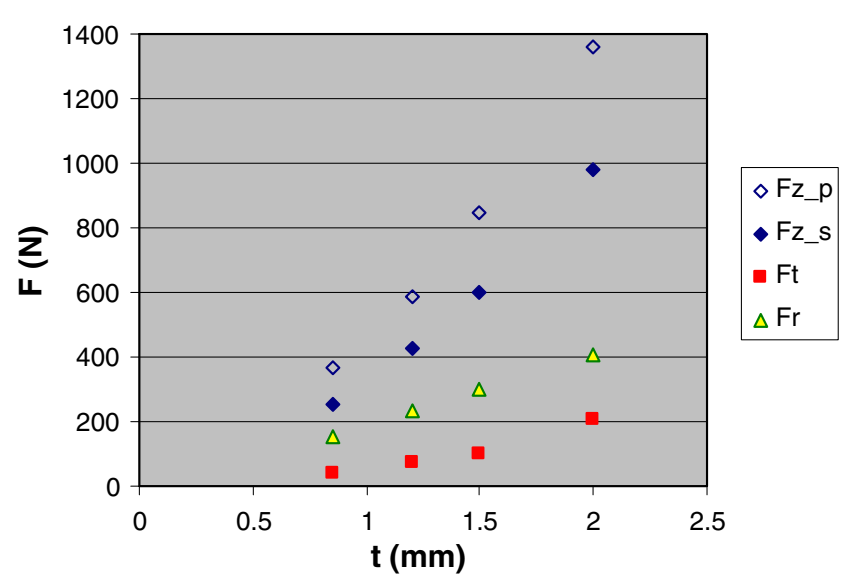

a - linear plot

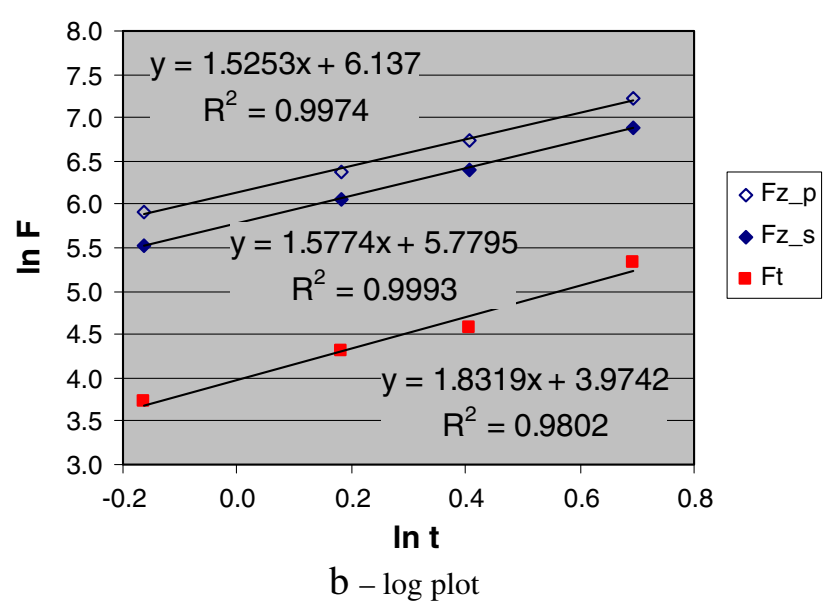

Fig. 9 Experimental forces for AA3003 in function of the sheet thickness (other parameters: $\alpha=70^{\circ}, d_{\mathrm{t}}=10 \mathrm{~mm}, \Delta z=0.5 \mathrm{~mm}$ ). a Linear plot; b log plot

The curves of Fz_p, Fz_s, and Ft have also been plotted in a $\log -\log$ diagram (Fig. 8b). It appears that there are linear relations between the logarithm of these variables and the logarithm of the sheet thickness.

Since for a wall angle of $50^{\circ}$, hardly any force peak can be observed, it is normal that the measurement points of $\mathrm{Fz} \_\mathrm{p}$ and $\mathrm{Fz}_{\mathrm{s}} \mathrm{s}$ are very close to each other. For that reason, similar tests have been performed for wall angles of $60^{\circ}$ and $70^{\circ}$. Results for $70^{\circ}$ are shown in Fig. 9a, b.

The linear relationship in the log-log diagram remains valid.

\subsection{Influence of the depth increment}

Tests have been performed with depth increments $(\Delta z)$ of $0.25,0.381,0.50,0.75$, and $1.00 \mathrm{~mm}$, keeping the other parameters at their standard values (i.e., $\alpha=50^{\circ}, d_{\mathrm{t}}=10 \mathrm{~mm}$, $t=1.2 \mathrm{~mm}$ ). Results are plotted in Fig. 10a.

The curves of Fz_p, Fz_s, and Ft have also been plotted in a log-log diagram (Fig. 10b). It appears that there are linear relations between the logarithm of these variables and the logarithm of the depth increment.

Summarized, we can conclude that:

For there is a linear relation with all the considered

Fz_p, parameters in logarithmic scale.

For there is a linear relation with all the parameters in

Fz_s, $\quad \operatorname{logarithmic}$ scale, except $\alpha$. Fz_s is proportional to $\alpha \cdot \cos \alpha$.

For Ft, there is a linear relation with $t$ and $\Delta z$ in a logarithmic scale. Since for the chosen standard working conditions, Ft was nearly constant in function of the tool diameter, and it is also a constant in logarithmic scale.

For Fr, the value of Fr varies from negative values for relative small wall angles to positive values for larger wall angles.

According to these conclusions, for each material, two series of experiments were planned: firstly, "wall angle

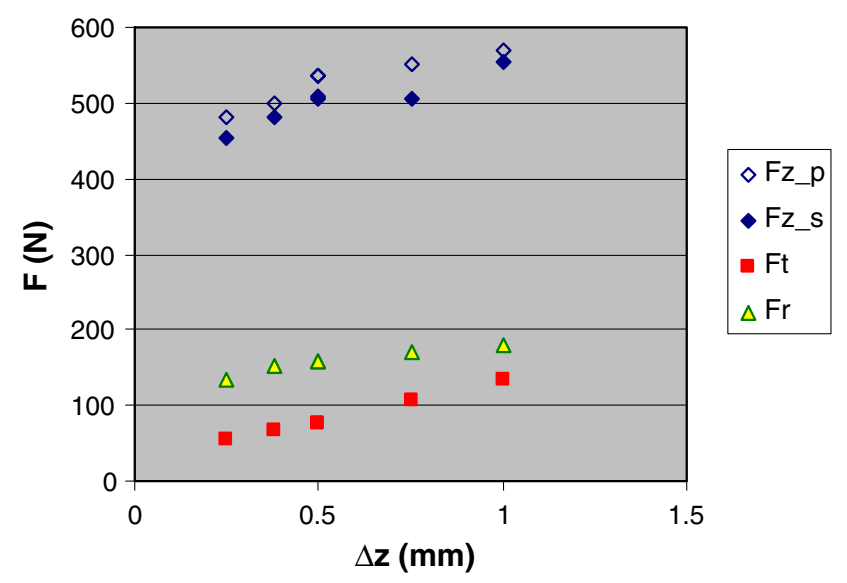

$\mathrm{a}$ - linear plot

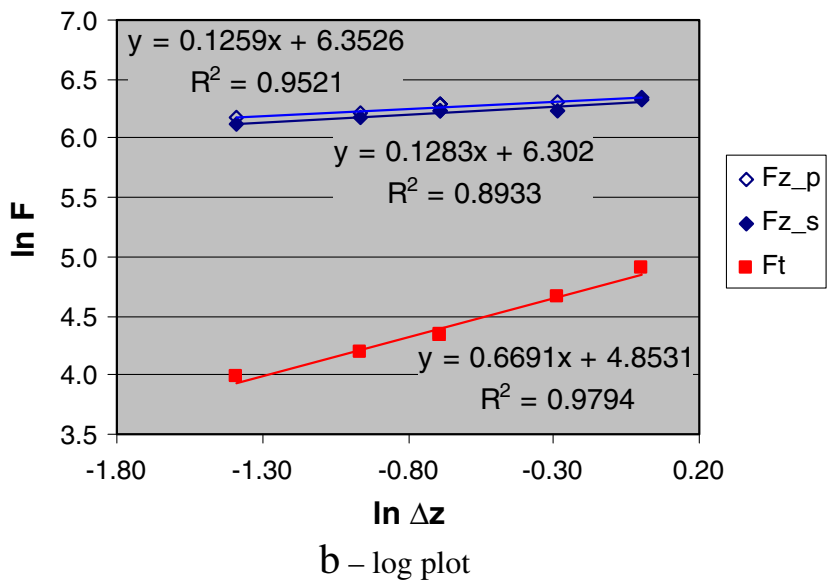

Fig. 10 Experimental forces for AA3003 in function of the depth increment (other parameters at standard settings: $\alpha=50^{\circ}, d_{\mathrm{t}}=10 \mathrm{~mm}$, $t=1.2 \mathrm{~mm}$ ). a Linear plot; b log plot 
tests" for which the sensitivity to $\alpha$ is recorded with small $\alpha$-increments till failure of the material (the other parameters being kept at standard values), and secondly, "factorial $2^{n}$ tests" in which all combination of two levels of each parameter (including $\alpha$ ) are covered.

- For Fz_p, Fz_s, and Ft, the aim is to establish regression equations in function of the parameters $t, \alpha, d_{t}$, and the scallop height $\Delta h$ (see Section 5). Since regression equations from factorial $2^{n}$ tests are simple linear interpolations between results, the relations between the variables and the parameters have to be linear. As it has been shown, this condition is fulfilled when we treat the logarithm of the variables and the parameters except for $\alpha$. In order to manage the special sensitivity to $\alpha$, a new variable has been introduced: $F 1$, which is Fz_s divided by $(\alpha \cos \alpha)$ and the regression equations have been established for $F 1$. Finally, the regression equation for $\mathrm{Fz}_{-} \mathrm{s}$ is obtained by simply multiplying the one for $F 1$ by $(\alpha \cos \alpha)$. For the regression equations presented in this paper, only influences and interactions higher than 5\% were taken into account.

- For Fr, an analytical relation between the Fr and Fz components will be discussed and the link to the process geometry will be analyzed in Section 7 .

\section{Investigated materials and working conditions}

Five materials, strongly differentiated by the tensile strength $\left(R_{\mathrm{m}}\right)$, have been studied:

- A soft Al alloy: AA3003, $R_{\mathrm{m}}=103 \mathrm{~N} / \mathrm{mm}^{2}$, thickness 0.85 and $1.5 \mathrm{~mm}$

- An Al-Mg alloy: AA5754, $R_{\mathrm{m}}=247 \mathrm{~N} / \mathrm{mm}^{2}$, thickness 1.0 and $1.5 \mathrm{~mm}$

- A deep drawing steel: DC01, $R_{\mathrm{m}}=357 \mathrm{~N} / \mathrm{mm}^{2}$, thickness 0.5 and $1.15 \mathrm{~mm}$

- A stainless steel: AISI $304, R_{\mathrm{m}}=660 \mathrm{~N} / \mathrm{mm}^{2}$, thickness 0.4 and $0.8 \mathrm{~mm}$
- A spring steel $65 \mathrm{Cr} 2, R_{\mathrm{m}}=1,064 \mathrm{~N} / \mathrm{mm}^{2}$, thickness $0.5 \mathrm{~mm}$ only

The influence of the working conditions has been examined using the following parameter settings:

- The wall angle $(\alpha)$, between $10^{\circ}$ and the failing angle

- The tool diameter $\left(d_{\mathrm{t}}\right)$, between 10 and $25 \mathrm{~mm}$

- The sheet thicknesses $(t)$, depending on the material

- The scallop height $(\Delta h)$, between 0.005 and $0.015 \mathrm{~mm}$

The scallop height $\Delta h$ is related to the depth increment $\Delta z$ taking the tool diameter and the wall angle into account. It is more convenient to use the scallop height as parameter than the depth increment since the scallop height is a surface quality determining parameter (Fig. 11).

The relation between $\Delta z$ and $\Delta h$ is

$\Delta z=2 \sin \alpha \sqrt{\Delta h\left(d_{\mathrm{t}}-\Delta h\right)} \approx 2 \sin \alpha \sqrt{\Delta h d_{\mathrm{t}}}$

The relationship between the forces and $\Delta h$ instead of $\Delta z$ (as shown in Fig. 10) is represented in Fig. 12.

The conclusion concerning the influence of $\Delta z$ on the force components remains valid for $\Delta h$.

\section{Experimental results and derived forces equations}

As an example, the results for DC01 are graphically represented in Figs. 13 and 14. In Fig. 14, Fz_p is not shown since in many cases no peak is noticeable. This representation allows to easily visualize the relative importance of the three force components and the influence of the parameters. The double points close to each other on the graphs correspond to the low and high scallop height (the higher $\Delta h$ yielding the highest force).

Detailed regression equations were obtained for the five studied materials. The uncertainty of the predicted force component values is $6 \%$. An example is given in the Appendix for DC01. It will be noticed that for $\mathrm{Fz} \_\mathrm{p}$ and $F 1$, only one interaction term is needed.
Fig. 11 The scallop height $\Delta h$ versus the depth increment $\Delta z$
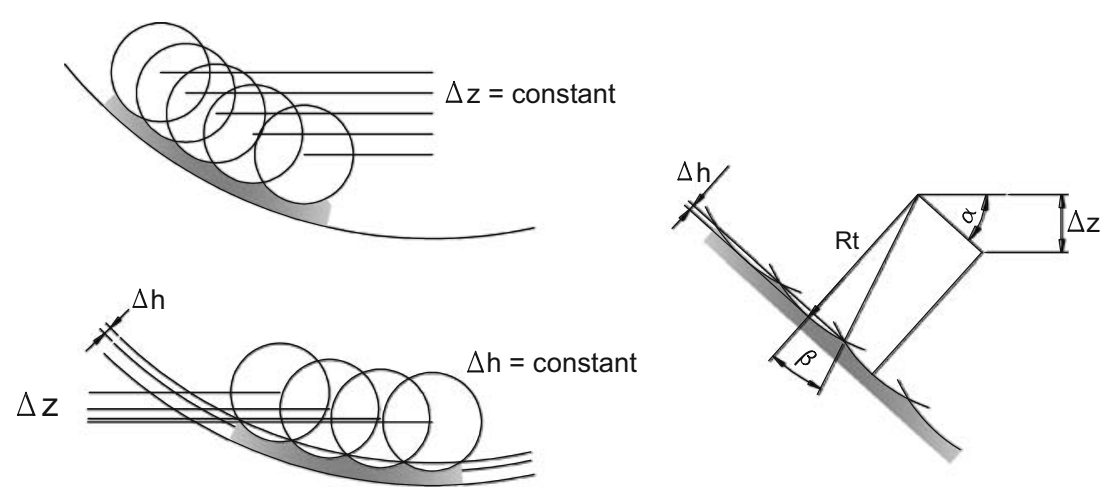


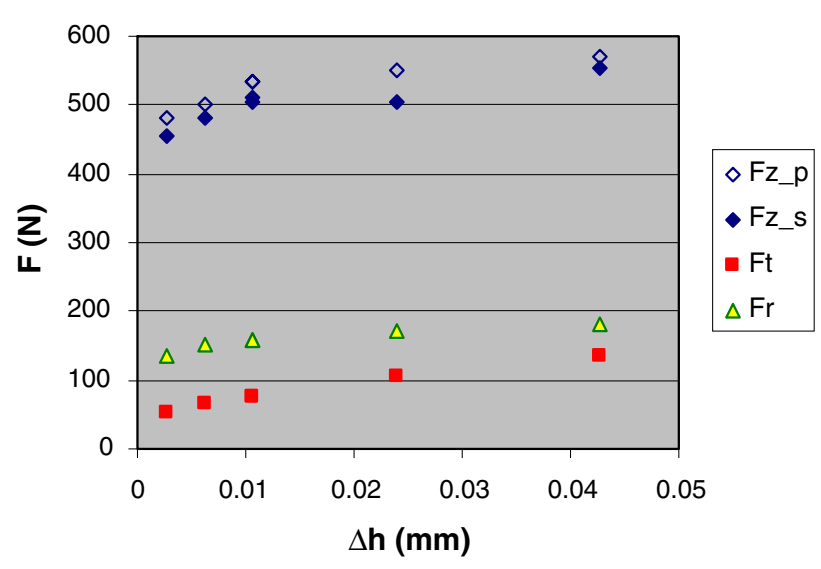

$\mathrm{a}-$ linear plot

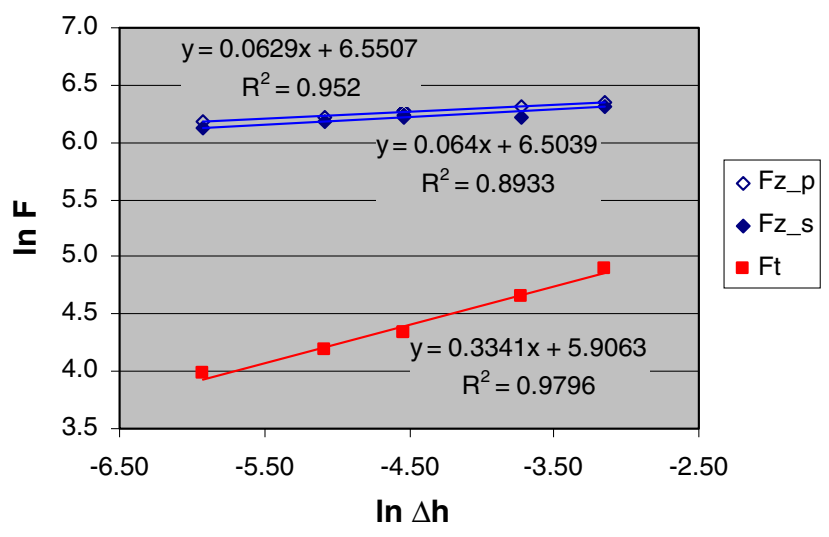

$\mathrm{b}-\log$ plot

Fig. 12 Experimental forces for AA3003 in function of the scallop height (other parameters at standard settings: $\alpha=50^{\circ}, d_{\mathrm{t}}=10 \mathrm{~mm}, t=$ $1.2 \mathrm{~mm}$ ). a Linear plot; b log plot

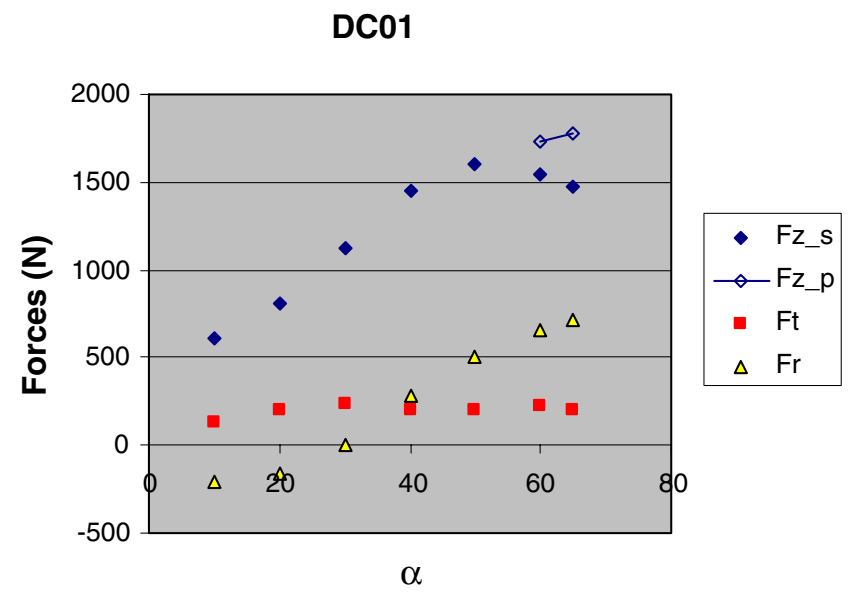

Fig. 13 Influence of the wall angle $\alpha$ on the three force components in steady state (plus Fz_p) for DC01, $t=1.15 \mathrm{~mm}, d_{\mathrm{t}}=10 \mathrm{~mm}, \Delta h=$ $0.005 \mathrm{~mm}$

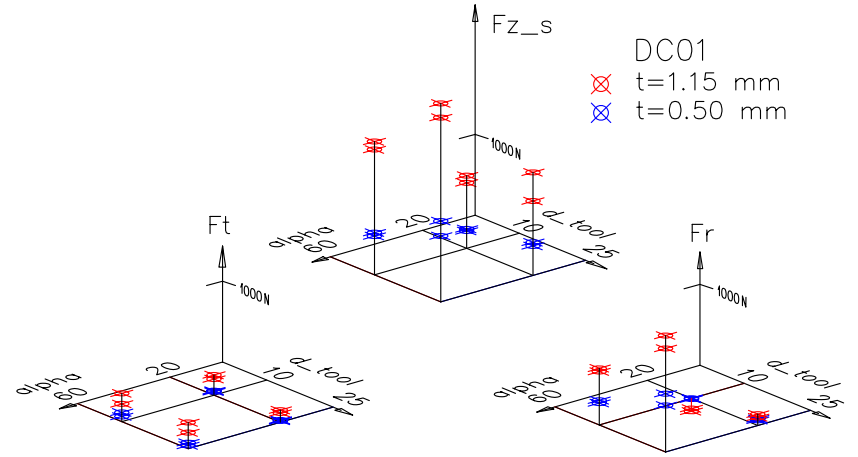

Fig. 14 Influence of the parameters (two levels) on the three force components in steady state

The regression equations presented hereafter are truncated: only the factors depending on the direct influences are shown, which means that the factors depending on interactions of the first and higher order are neglected. So, the regression equations become power functions but with a larger uncertainty: the largest error is indicated between square brackets in Eqs. 7, 8, 9, 10, 11, 12, 13, 14, 15, 16, 17, 18, 19, 20, and 21. Note that for $\mathrm{Ft}$ the relative error can be large, but its absolute value remains small. In the next formulae $\alpha$ is expressed in degrees.

AA3003

$\mathrm{Fz} \_\mathrm{s}=8.35 t^{1.58} d_{\mathrm{t}}^{0.35} \Delta h^{0.09} \alpha \cos \alpha \quad \cdots \quad[12.2 \%]$

Fz_p $=19.1 t^{1.63} d_{\mathrm{t}}^{0.36} \Delta h^{0.09} \alpha^{0.65} \quad \cdots \quad[9.6 \%]$

$\mathrm{Ft}=63.4 t^{2.09} d_{\mathrm{t}}^{-0.24} \Delta h^{0.35} \alpha^{0.57} \quad \cdots \quad[27.9 \%]$

$$
\text { AA5754 (AlMg3) }
$$

Fz_s $=15.86 t^{1.72} d_{\mathrm{t}}^{0.40} \Delta h^{0.08} \alpha \cos \alpha \cdots[14.9 \%]$

Fz_p $=15.86 t^{1.72} d_{\mathrm{t}}^{0.40} \Delta h^{0.08} \alpha \cos \alpha$

... (identicalto Fz_s, nopeak)

$\mathrm{Ft}=575.5 t^{2.37} d_{\mathrm{t}}^{0.49} \Delta h^{0.35} \alpha^{0.28} \quad \cdots \quad[25.6 \%]$ 


$$
\begin{aligned}
& \text { DC01 } \\
& \text { FZ_s }=16.26 t^{1.35} d_{\mathrm{t}}^{0.48} \Delta h^{0.12} \alpha^{1.11} \cos \alpha \cdots[13.4 \%] \\
& \text { Fz_p }=40.7 t^{1.42} d_{\mathrm{t}}^{0.48} \Delta h^{0.12} \alpha^{0.73} \quad \cdots \quad[15.9 \%] \\
& \mathrm{Ft}=662.1 t^{1.82} d_{\mathrm{t}}^{-0.52} \Delta h^{0.39} \alpha^{0.54} \quad \cdots \quad[33.3 \%]
\end{aligned}
$$$$
\text { AISI } 304
$$$$
\text { Fz_s }=35.7 t^{1.61} d_{\mathrm{t}}^{0.42} \Delta h^{0.08} \alpha^{0.99} \quad \ldots \quad[27.1 \%]
$$$$
\text { Fz_p }=40.7 t^{1.63} d_{\mathrm{t}}^{0.39} \Delta h^{0.07} \alpha^{0.97} \quad \cdots \quad[28.3 \%]
$$$$
\mathrm{Ft}=33248 t^{3.34} d_{\mathrm{t}}^{-1.13} \Delta h^{0.38} \alpha^{0.42} \quad \cdots \quad[145.8 \%]
$$$$
65 \mathrm{Cr} 2(t=0.5 \mathrm{~mm})
$$$$
\mathrm{Fz}_{-} \mathrm{s}=11.28 d_{\mathrm{t}}^{0.75} \Delta h^{0.14} \alpha \cos \alpha \quad \cdots \quad[6.7 \%]
$$$$
\text { Fz_p }=11.28 d_{\mathrm{t}}^{0.75} \Delta h^{0.14} \alpha \cos \alpha
$$$$
\text { ... (identical toFz_s, nopeak) }
$$

$$
\mathrm{Ft}=448 d_{\mathrm{t}}^{-0.80} \Delta h^{0.45} \alpha^{0.75} \quad \ldots \quad[32.3 \%]
$$

$$
\text { elements over the thickness were used, except for the }
$$
small submodel, having five elements over the sheet thickness. The global model features (non-physical) symmetry boundary conditions at its $0^{\circ}$ and $40^{\circ}$ edges and a boundary condition of fixed nodes at the model edge over the backing plate. The boundary conditions on the nodes on the four edges of the large submodel are obtained from the solution (nodal displacements) of the global model in the vicinity of the edges of the large submodel, with the use of linear interpolation. This was achieved in an automated way using the submodeling option available in Abaqus. For the small submodel, the solution of the large submodel was used. The calculation times of any of these models was less than 2 days on a 2.4-GHz CPU. More details can be found in [14]. The contact area of the global model was found to depend heavily on the position of the tool with respect to the neighboring nodes of the sheet, and the forming force components showed consequently heavy fluctuations during a single tool contour, as shown in [15]. The contact area becomes much more "mesh independent" for the large submodel, and even more so for the local submodel. This allows to study the shape of the contact area between the tool and the sheet and the distribution of the contact pressure with acceptable precision. The results of the small submodel with different parameter settings are shown in Fig. 15, except for the case with $60^{\circ}$ wall angle and $25 \mathrm{~mm}$ tool diameter. Here, the large submodel is 
Fig. 15 Contact area and contact pressure for different combinations of wall angle and tool diameter for AA3003 $1.2 \mathrm{~mm}$. The figures show top views of the tool and the contact zone of the cone represented in the small sketch above (the upper part of each figure corresponds to the cone wall and the lower part to the cone bottom). The tool is shown with red lines and its movement in the figures is from right to left. The approximate dimensions of the represented sheet surface in the respective models are given between brackets
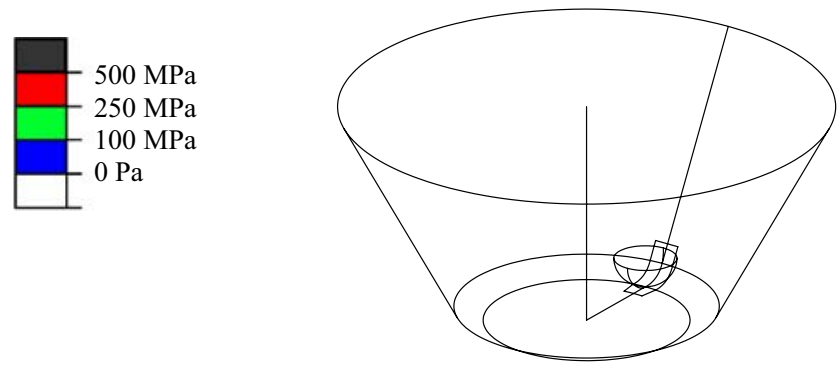

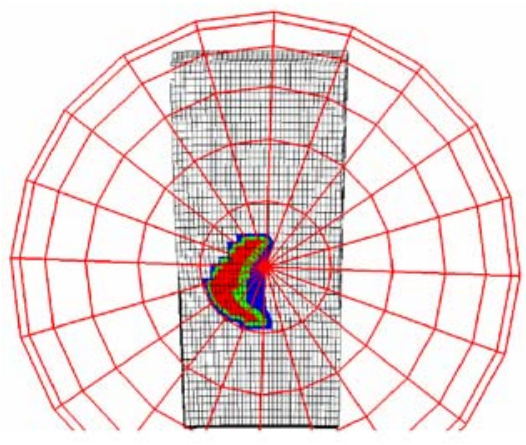

Cone $20^{\circ} \mathrm{d}_{\mathrm{t}} 10 \mathrm{~mm}(7.0 \mathrm{~mm} * 3.2 \mathrm{~mm})$

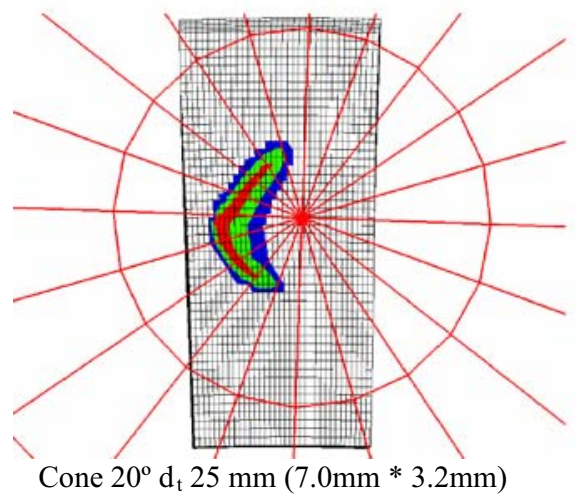

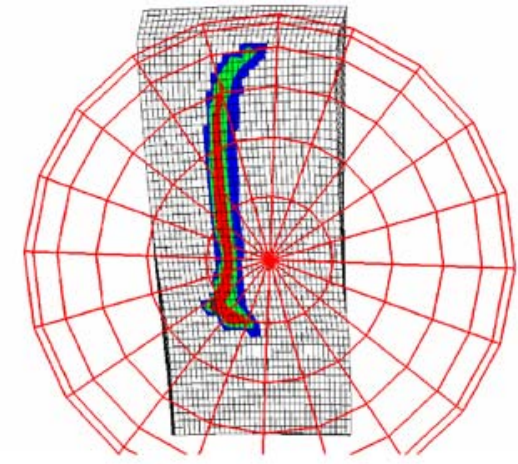

Cone $60^{\circ} \mathrm{d}_{\mathrm{t}} 10 \mathrm{~mm}(7.0 \mathrm{~mm} * 3.7 \mathrm{~mm})$

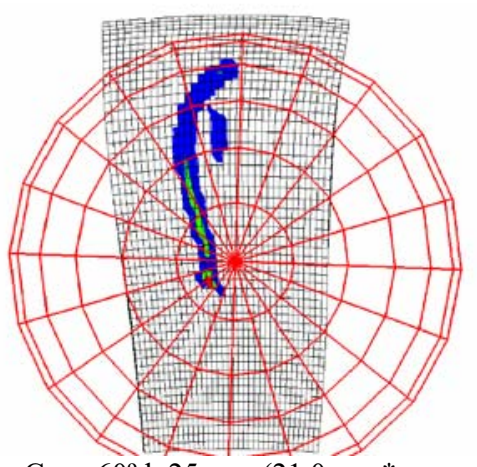

Cone $60^{\circ} \mathrm{d}_{\mathrm{t}} 25 \mathrm{~mm}(21.0 \mathrm{~mm} *$ $11.9 \mathrm{~mm})$ shown since the contact zone could not be fully covered by the small submodel.

From these results, we can deduce that the contact area may be approximated by a ribbon of constant width and that the contact pressure has approximately a constant distribution profile along the ribbon. The length of the ribbon depends on three angles (Fig. 16): the scallop angle $\beta$ (angle comprising a halve "wave" at the surface of the cone (whose expression can be derived from Fig. 11), known), the wall angle $\alpha$ (known), and the "groove" angle $\gamma$ (angle comprising the arc between the top of the tool and the end of contact with the groove at the bottom of the cone). This last angle is important since it can be larger than the actual wall angle.

Projected in the plane $z-r$, the contact forces are acting as depicted in Fig. 17. The orientation of the total force $\mathbf{R}$ follows from the assumption that the contact pressure has a constant distribution profile. This leads to a first relation between Fr and Fz:

$\mathrm{F}_{\mathrm{r}}=\mathrm{F}_{\mathrm{z}} \tan \frac{\alpha+\beta-\gamma}{2}$

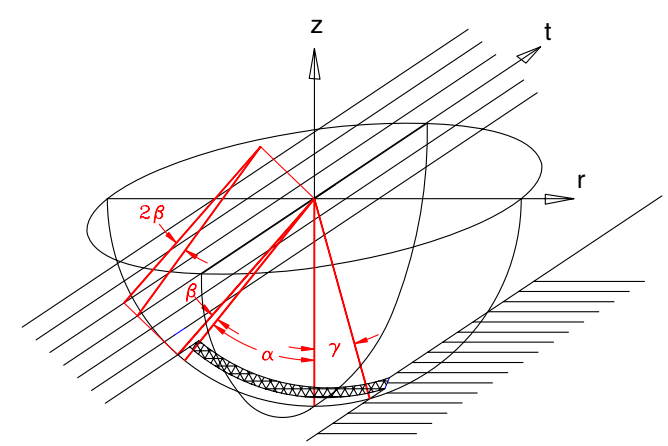

Fig. 16 The modeled contact area 


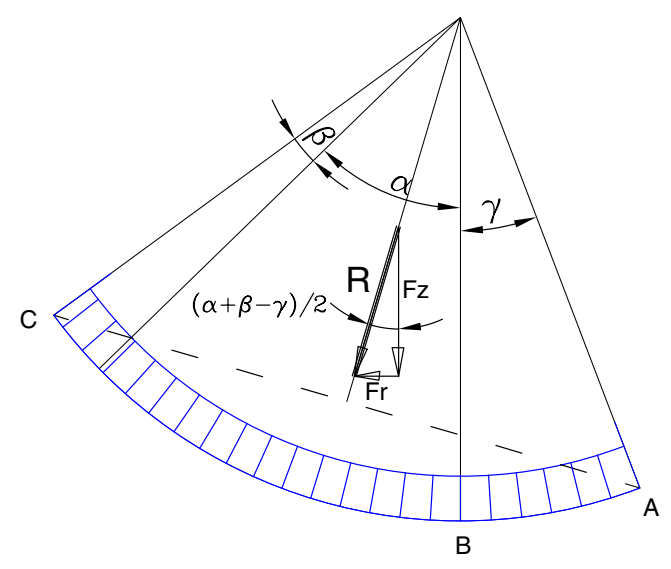

Fig. 17 Resultant forces

where

$$
\begin{aligned}
\beta & =\arccos \left(1-2 \Delta h / d_{\mathrm{t}}\right) \\
& =\arcsin \left(\Delta z /\left(d_{\mathrm{t}} \sin \alpha\right)\right)
\end{aligned}
$$

From measurements of the profiles of cones at the level of the cone bottom, it appears that the angle $\gamma$ is mainly depending on the tool diameter and is nearly independent of the wall angle. This can also be deduced from the results of the FE simulations (Fig. 15), considering the tool diameter and the length from the tool top to the ultimate contact point.

The angle $\gamma$ may be approximated by the following expression

$\gamma=0.3\left(d_{\mathrm{t}} / 10\right)^{-c} \quad(\mathrm{rad}) \quad$ or

$\gamma=17.2\left(d_{\mathrm{t}} / 10\right)^{-c}(\mathrm{deg})$

where

$d_{\mathrm{t}}$ is the diameter of the tool in $\mathrm{mm}$

$c=2.54$ for aluminium alloys and DC01 and 1.20 for AISI 304

From Eqs. 22 and 24, it follows that

$\mathrm{F}_{\mathrm{r}}=\mathrm{F}_{\mathrm{z}} \tan \frac{\alpha+\beta-17.2\left(d_{\mathrm{t}} / 10\right)^{-c}}{2}$

This formula has been checked with all the force measurements that have been performed for the five selected materials. It appears that Eq. 25 yields a good approximation in many cases but not all. In order to improve the precision, a small correction term has been introduced. This correction, based on the measurements, is a polynomial that has been established per material. The results of the theoretical computations of Fr and the effect of the correction can be seen in Fig. 18, for the case of DC01.

$\mathrm{F}_{\mathrm{r}}=\mathrm{F}_{\mathrm{z}}\left[\tan \frac{\alpha+\beta-17.2\left(d_{\mathrm{t}} / 10\right)^{-c}}{2}+P\left(\alpha, d_{\mathrm{t}}, t, \Delta h\right)\right]$

As an example, the polynomial correction for DC01 is

$$
\begin{aligned}
\mathrm{P}(\alpha, & \left.d_{\mathrm{t}}, t, \Delta h\right)=-0.118 \mathrm{E}-01 \\
& -0.202 \mathrm{E}+00 *(t-0.825 \mathrm{E}+00) \\
& +0.345 \mathrm{E}-02 *(d-0.175 \mathrm{E}+02) \quad \text { where } d \text { is } d_{t} \text { in } \mathrm{mm} \\
& +0.387 \mathrm{E}-02 *(a-0.400 \mathrm{E}+02) \quad \text { where } a \text { is } \alpha \text { in } \mathrm{deg} \\
& +0.569 \mathrm{E}-02 *(t-0.825 \mathrm{E}+00) *(d-0.175 \mathrm{E}+02) \\
& -0.216 \mathrm{E}-03 *(d-0.175 \mathrm{E}+02) *(a-0.400 \mathrm{E}+02)
\end{aligned}
$$

\section{Generalized formula for the $\mathrm{Fz}_{-} \mathrm{s}$ force}

Using a common set of process parameters for the different materials (excluding $65 \mathrm{Cr} 2$ because this material has been tested in a thickness too far from the thickness range of the other materials since the forces would otherwise exceed the measurement capacity of the equipment used), the corresponding "reference force Fz s" was computed for each material using Eqs. 7, 10, 13, and 16. The common settings are:

- $t=0.9 \mathrm{~mm}$ : this value was chosen in order to assure minimal extrapolation in the computations (highest thickness for AISI is $0.8 \mathrm{~mm}$ and lowest thickness for AlMg3 is $1 \mathrm{~mm}$, see paragraph 3 )

- $d_{\mathrm{t}}=15 \mathrm{~mm}, \Delta h=0.010 \mathrm{~mm}, \alpha=45^{\circ}:$ chosen as average values

We can see in Fig. 19 that a simple proportionality can be observed between the "reference force $\mathrm{Fz}_{-} \mathrm{s}$ "

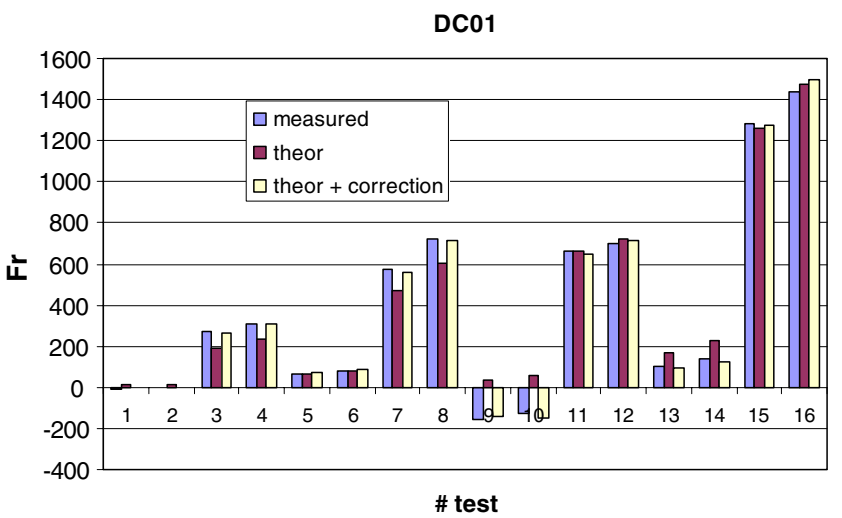

Fig. 18 Results of the theoretical computation of Fr without and with correction 


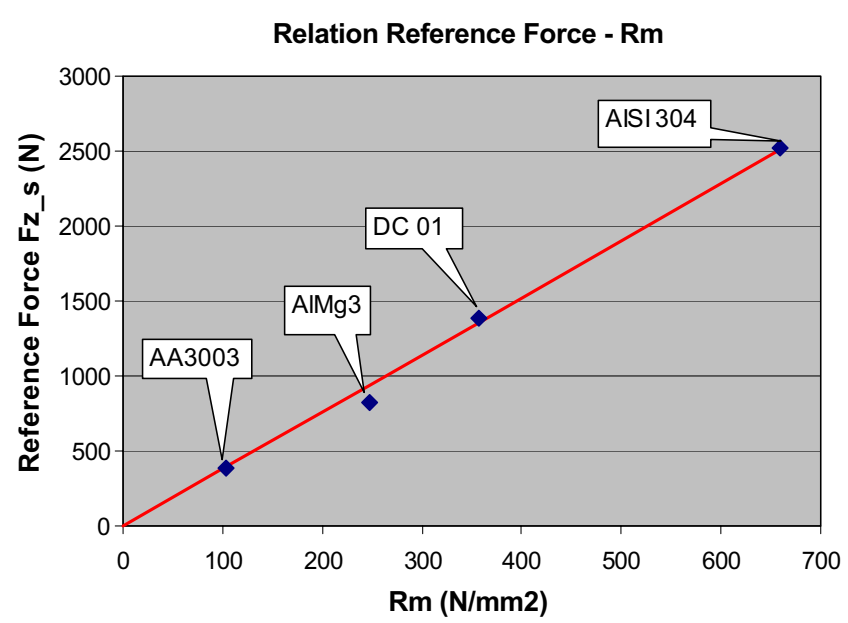

Fig. 19 Proportionality between the "reference force" and the tensile strength $R_{\mathrm{m}}$

and the tensile strength $R_{\mathrm{m}}$. This can be expressed as follows:

$\operatorname{Fz} \_$REF $_{\text {RE }}(\mathrm{N})=3.8 R_{\mathrm{m}}\left(\mathrm{N} / \mathrm{mm}^{2}\right)$

Since the influence exponents of the parameters in the Fz_s (Eqs. 7, 10, 13, and 16) show a limited spread, a generalized formula using averaged exponents can be considered:

Fz_s $\propto t^{1.57} d_{\mathrm{t}}^{0.41} \Delta h^{0.09} \alpha \cos \alpha$

Combining Eqs. 28 and 29, an approximated generalized formula is obtained which allows to predict the axial force $\mathrm{Fz}_{-} \mathrm{s}$ for any material based on the tensile strength only:

F__s $=0.0716 R m t^{1.57} d_{\mathrm{t}}^{0.41} \Delta h^{0.09} \alpha \cos \alpha$

where $\mathrm{Fz}_{-} \mathrm{s}$ is expressed in $\mathrm{N}, R_{\mathrm{m}}$ in $\mathrm{N} / \mathrm{mm}^{2}, t$ in $\mathrm{mm}, d_{\mathrm{t}}$ in $\mathrm{mm}, \Delta h$ in $\mathrm{mm}$, and $\alpha$ in deg.

The precision of this formula has been checked by comparing the calculated forces with the experimental test results. The errors were determined and sorted in classes: $10 \%, 15 \%, 20 \%, \ldots$ and the occurrences were quantified This allowed to derive a cumulative graph giving the probability for the a maximal error limit (Fig. 20). This graph allows to evaluate the expected precision of the predictions. For example, a relative error of maximum $15 \%$ was obtained in $77 \%$ of all cases.

To illustrate the generic applicability of Formula 30, a force prediction was calculated and experimentally verified for a material not used for deriving the relation. For this purpose, aluminum 2024 was used. The tensile strength of this material is $435 \mathrm{~N} / \mathrm{mm}^{2}$. Prediction results and measurements of $\mathrm{Fz}_{-} \mathrm{s}$ are shown in Table 1.

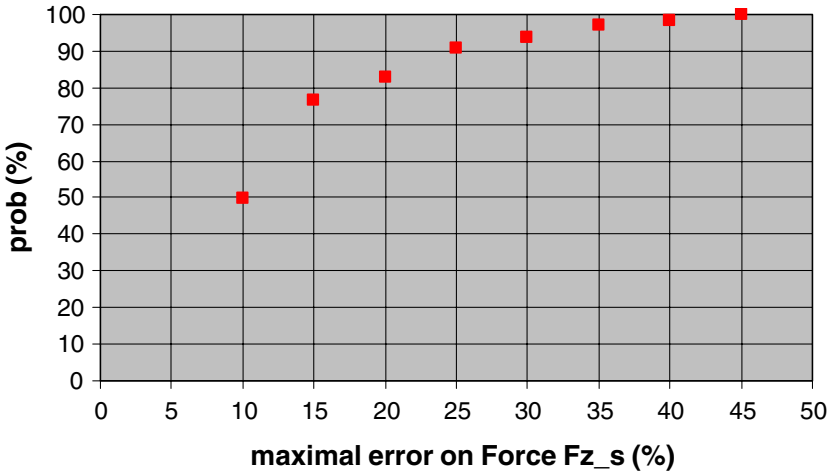

Fig. 20 Relation error-probability of occurrence

\section{Conclusion}

For five studied materials (AA3003, AA5754 (AlMg3), DC01, AISI 304, 65Cr2), regression formulae were obtained that allow to compute the axial (Fz_p and $\mathrm{Fz}_{-} \mathrm{s}$ ) and tangential (Ft) components of the forming force in steady state with a good precision (largest error, $6 \%)$.

Based on an analytical force analysis of the process on one hand and on the results of FEM simulations on the other hand, a formula to compute the radial component $(\mathrm{Fr})$ has been deduced. This component is linked to the value of the axial component $\mathrm{Fz}_{-} \mathrm{s}$.

Table 1 Computed and measured values of $\mathrm{Fz}_{-} \mathrm{s}$ for Al 2024 for different parameter settings

\begin{tabular}{llllllr}
\hline $\begin{array}{l}t \\
(\mathrm{~mm})\end{array}$ & $\begin{array}{l}d_{\mathrm{t}} \\
(\mathrm{mm})\end{array}$ & $\begin{array}{l}\alpha \\
(\mathrm{deg})\end{array}$ & $\begin{array}{l}\Delta h \\
(\mathrm{~mm})\end{array}$ & $\begin{array}{l}\text { Fz_s } \\
\text { measured } \\
(\mathrm{N})\end{array}$ & $\begin{array}{l}\text { Fz_s } \\
\text { computed } \\
(\mathrm{N})\end{array}$ & \multicolumn{1}{l}{$\begin{array}{l}\text { Error } \\
(\%)\end{array}$} \\
\hline 0.4 & 10 & 20 & 0.005 & 177.7 & 192.9 & 8.6 \\
0.4 & 10 & 20 & 0.015 & 197.3 & 213.0 & 7.9 \\
0.4 & 10 & 35 & 0.005 & 333.4 & 320.6 & -3.8 \\
0.4 & 10 & 35 & 0.015 & 368.7 & 354.0 & -4.0 \\
0.4 & 20 & 20 & 0.005 & 300.9 & 256.4 & -14.8 \\
0.4 & 20 & 20 & 0.015 & 341.5 & 283.0 & -17.1 \\
0.4 & 20 & 35 & 0.005 & 581.8 & 426.0 & -26.8 \\
0.4 & 20 & 35 & 0.015 & 618.7 & 470.3 & -24.0 \\
1 & 10 & 20 & 0.005 & 767.6 & 813.2 & 5.9 \\
1 & 10 & 20 & 0.015 & 822.0 & 897.7 & 9.2 \\
1 & 10 & 35 & 0.005 & $1,244.6$ & $1,351.4$ & 8.6 \\
1 & 10 & 35 & 0.015 & $1,418.0$ & $1,491.9$ & 5.2 \\
1 & 20 & 20 & 0.005 & $1,092.5$ & $1,080.5$ & -1.1 \\
1 & 20 & 20 & 0.015 & $1,229.6$ & $1,192.8$ & -3.0 \\
1 & 20 & 35 & 0.005 & $1,825.2$ & $1,795.6$ & -1.6 \\
1 & 20 & 35 & 0.015 & $2,056.5$ & $1,982.2$ & -3.6 \\
\hline & & & & & & \\
\hline
\end{tabular}


For any other material, the use of an approximate formula for the estimation of the $\mathrm{Fz}_{-} \mathrm{s}$ force component is suggested. This estimation method uses the tensile strength of the concerned material as only material input parameter.

Acknowledgement The authors would like to acknowledge the financial support from the Institute for the Promotion of Innovation by Science and Technology in Flanders (IWT). This study has been conducted in the framework of the SEMPER project (Sheet Metal Oriented Prototyping and Rapid Manufactur- ing). Further support from the Research Foundation-Flanders (FWO) is acknowledged.

\section{Appendix-Regression equations for DC01}

The regression equations have been generated automatically by our analysis software in the format of FORTRAN subroutines, so they can easily be integrated in any other software by simple copy-paste.

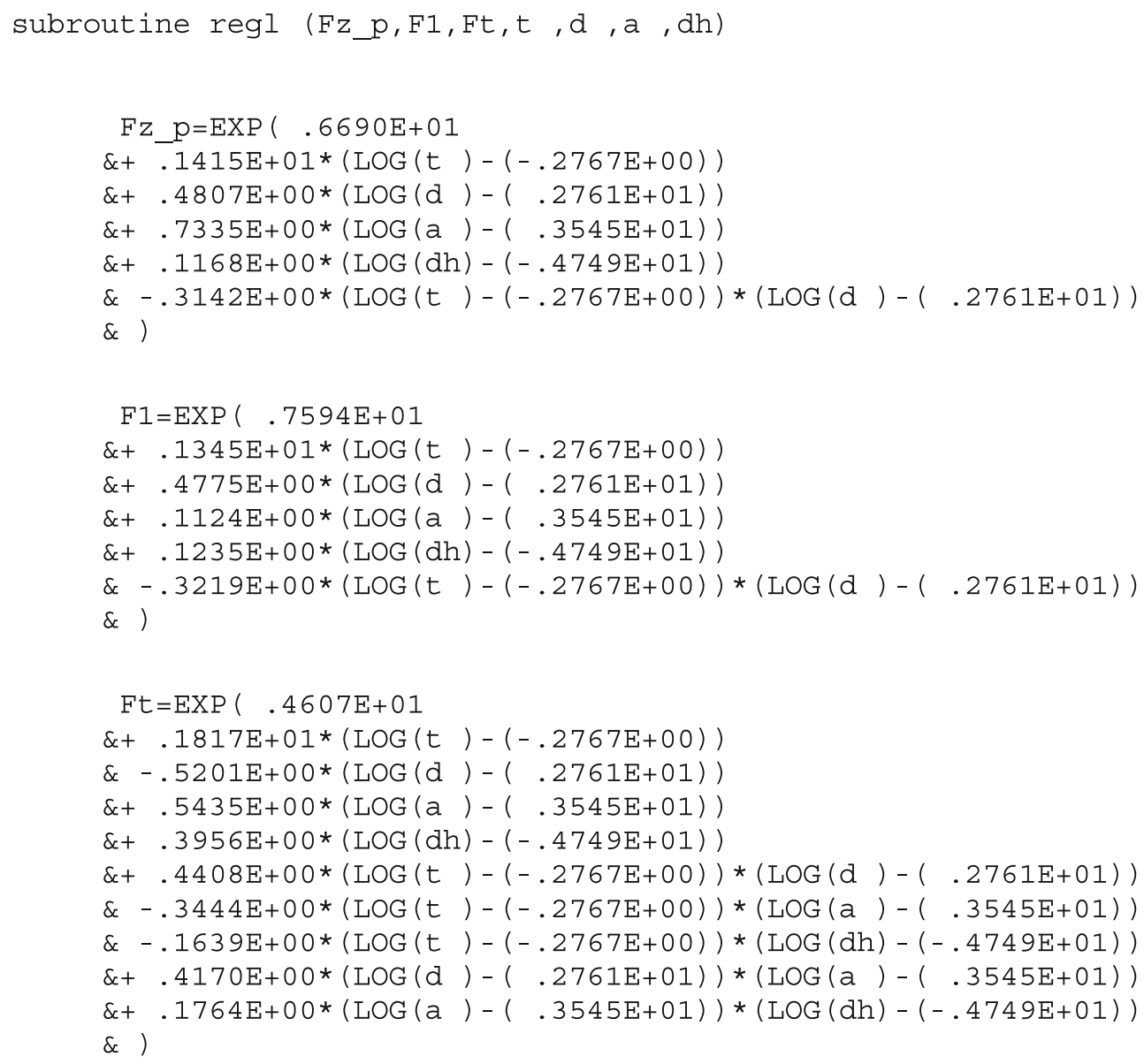

\section{References}

1. Jeswiet J, Micari F, Hirt G, Bramley A, Duflou J, Allwood J (2005) Asymmetric single point incremental forming of sheet metal, Annals of CIRP - Manufacturing Technology, vol 54/2/ 2005, pp. 623-650

2. Ambrogio G, Duflou J.R, Filice L, Aerens R (2007) Some considerations on force trends in Incremental Forming of different materials, $10^{\text {th }}$ ESAFORM conference on material forming, AIP Conference Proceedings, vol 907, pp 193-198

3. Jeswiet J, Duflou JR, Szekeres A (2005) Forces in single point and two point incremental forming. Adv Mat Res 6-8:449-456

4. Szekeres A, Ham M, Jeswiet J (2007) Sheet metal 2007, force measurement in pyramid shaped parts with a spindle mounted force sensor. Key Eng Mater 344:551-558

5. Petek A, Kuzman K, Kopac J (2005) Forces and deformations analysis of incremental sheet metal forming, CAM3S, $11^{\text {th }}$ 
International Scientific Conference on temporary achievements in mechanics, manufacturing and materials science

6. Iseki H (2001) An approximate deformation analysis and FEM analysis for the incremental bulging of sheet metal using a spherical roller. J Mater Process Technol 111:150-154

7. Pohlak M, Majak J, Küttner R (2007) Manufacturability and limitations in incremental sheet forming. Proc Est Acad Sci Eng 13(2):129-139

8. Silva MB, Skjoedt M, Martins PAF, Bay N (2008) Revisiting the fundamentals of single point incremental forming by means of membrane analysis. Int J Mach Tool Manuf 48:7383

9. Duflou JR, Tunçkol Y, Szekeres A, Vanherck P (2007) Experimental study on force measurements for single point incremental forming. J Mater Process Technol 189(1-3, 6):65-72

10. Duflou JR, Szekeres A, Vanherck P (2005) Force measurements for single point incremental forming: an experimental study. Adv Mater Res 6-8:441-448
11. Duflou J.R, Tunçkol Y, Aerens R (2007) Force analysis for single point incremental forming, Proceedings of the 12th Internat. Conference on Sheet Metal, pp 543-550

12. Duflou J.R, Tunçkol Y (2006) Force modelling for single point incremental forming, Proceedings of the $9^{\text {th }}$ ESAFORM Conference on Material Forming, Glasgow, ISBN 83-89541-66-1, pp 287-290

13. Van Bael A, He S, Van Houtte P, Tunçkol Y, Verbert J, Duflou JR (2005) Study on the thinning during single point incremental forming of aluminium sheets, $24^{\text {th }}$ International Deep-Drawing Research Group Congress

14. Eyckens P, Van Bael A, Aerens R, Duflou JR, Van Houtte P (2008) Small-scale finite element modelling of the plastic deformation zone in the incremental forming process, Proceedings of the $11^{\text {th }}$ ESAFORM Conference on Material Forming

15. Eyckens P, He S, Van Bael A., Duflou J.R, Van Houtte P (2007) Finite element based formability predictions of sheets subjected to the incremental forming process, Proceedings of the 9th International Conference on Computational Plasticity (COMPLAS IX), pp. 529-532 